\title{
THE
}

\section{Associations between family food behaviors, maternal depression, and child weight among low-income children}

\author{
Karen McCurdy \\ University of Rhode Island, kmccurdy@uri.edu \\ Kathleen S. Gorman \\ University of Rhode Island, kgorman@uri.edu \\ Tiffani S. Kisler \\ University of Rhode Island, tkisler@uri.edu \\ Elizabeth Metallinos-Katsaras
}

Follow this and additional works at: https://digitalcommons.uri.edu/hdf_facpubs

This is a pre-publication author manuscript of the final, published article.

Creative Commons License

(c) (i) $\odot$

This work is licensed under a Creative Commons Attribution-Noncommercial-No Derivative Works 4.0 License.

\footnotetext{
Citation/Publisher Attribution

McCurdy, K., Gorman, K. S., Kisler, T., Metallinos-Katsaras, E. (2014). Associations between family food behaviors, maternal depression, and child weight among low-income children. Appetite, 79, 97-105. doi: 10.1016/j.appet.2014.04.015

Available at: https://doi.org/10.1016/j.appet.2014.04.015
}

This Article is brought to you for free and open access by the Human Development and Family Science at DigitalCommons@URI. It has been accepted for inclusion in Human Development and Family Science Faculty Publications by an authorized administrator of DigitalCommons@URI. For more information, please contact digitalcommons-group@uri.edu. 


\title{
Associations between family food behaviors, maternal depression, and child weight among low-income children
}

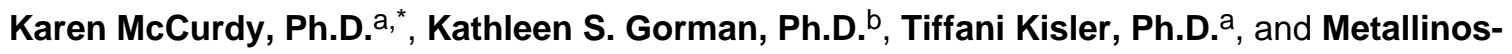 \\ Katsaras Metallinos-Katsaras, Ph.D., R.D. ${ }^{\mathrm{C}}$ \\ aHuman Development \& Family Studies, University of Rhode Island, 2 Lower College, Kingston, \\ $\mathrm{RI}, 02881$
}

${ }^{b}$ Psychology, University of Rhode Island, Kingston, RI, 02881

cNutrition, Simmons College, 300 The Fenway, Boston, MA, 02115

\section{Abstract}

\begin{abstract}
Although low-income children are at greater risk for overweight and obesity than their higher income counterparts, the majority of poor children are not overweight. The current study examined why such variation exists among diverse young children in poor families. Crosssectional data were collected on 164 low-income, preschool aged children and their mothers living in two Rhode Island cities. Over half of the sample was Hispanic (55\%). Mothers completed measures of family food behaviors and depression while trained assistants collected anthropometric data from children at seven day care centers and a Supplemental Nutrition Assistance Program outreach project. Multivariate analysis of covariance revealed that higher maternal depression scores were associated with lower scores on maternal presence when child eats $(P<.05)$, maternal control of child's eating routines $(P<.03)$, and food resource management skills $(P<.01)$, and with higher scores on child control of snacking $(P<.03)$ and negative mealtime practices $(P<.05)$. Multiple regression results revealed that greater maternal presence whenever the child ate was significantly associated with lower child BMI $z$ scores $(\beta=.166, P<$. 05). Logistic regression analyses indicated that higher scores on food resource management skills reduced the odds of child overweight (odds ratios $=.72-.95, P<.01$ ). Maternal depression did not modify the relationship between family food behaviors and child weight. Overall, caregiver presence whenever a child eats, not just at meals, and better parental food resource management skills may promote healthier weights in low-income preschoolers. Further research is needed to identify the mechanisms that connect caregiver presence and food resource management skills to healthier weights for this age group.
\end{abstract}

\footnotetext{
(C) 2014 Elsevier Ltd. All rights reserved.

*Corresponding author: kmccurdy @uri.edu, Phone 401-874-5960, FAX 401-874-4020.
}

Publisher's Disclaimer: This is a PDF file of an unedited manuscript that has been accepted for publication. As a service to our customers we are providing this early version of the manuscript. The manuscript will undergo copyediting, typesetting, and review of the resulting proof before it is published in its final citable form. Please note that during the production process errors may be discovered which could affect the content, and all legal disclaimers that apply to the journal pertain. 


\section{Keywords}

Child overweight; low-income; family meals; food resource management skills; young children

Child overweight is more highly concentrated among low-income children as compared to the general population. Nationally, $26.7 \%$ of the preschool-age population is overweight (Ogden, Carroll, Kit, \& Flegal, 2012). Among low-income households, those below 200\% of the federal poverty line, about one-third of preschool-aged children are overweight (Dalenius, Borland, Smith, Polhamus, \& Grummer-Strawn, 2012; Edmunds et al., 2006). Rates vary, however, by race and ethnicity. For example, low-income Hispanic preschoolaged children are more likely to be overweight or obese (35\%) than their non-Hispanic white (27.8\%) or non-Hispanic black counterparts (25.7) (Dalenius et al.). This high prevalence is of particular concern as studies suggest that experiencing overweight during the preschool years increases the likelihood of experiencing overweight in adolescence (Nader et al., 2006) and adulthood (Lin, Huang, \& French, 2004). Although most research links poverty and child weight, the majority of low-income preschool aged children are not overweight. This study examines why such variation exists among young children in poor families with a focus on family food behaviors that have been associated with income (Coon, Goldberg, Rogers, \& Tucker, 2001; Flores, Tomany-Korman \& Olson, 2005) and maternal depression, which disproportionately impacts low-income mothers (Ertel, RichEdwards, \& Koenen, 2011) and may inhibit the use of effective family food behaviors (McCurdy, Gorman \& Metallinos-Katsaras, 2010).

\section{Family food behaviors}

In studies of middle class and nationally representative samples, eating meals as a family has been linked to better dietary intake (Woodruff \& Harding, 2013). Findings are mixed regarding its association with child overweight (Gable, Chang, \& Krull, 2007; Hammons \& Fiese, 2011), though one recent review found a stronger relationship between eating family meals and lower weight among younger children as compared to adolescents (Valdes, Rodriguez-Artalejo, Casquero, \& Royo-Bordonada, 2012). Much of this research, however, is limited by single item measures of the family meal; the failure to consider other mealtime behaviors that may promote healthy food habits, such as consistent eating routines (Baughcum et al., 2001); a focus on samples with older children and youth (Kroller \& Warschburger, 2008); and limited attention to adult presence whenever child eating occurs, which may be of particular importance to the health of preschool aged children who eat several times a day (Ziegler, Hanson, Ponza, Novak, \& Hendricks, 2006). Further, although low-income and minority families have been found to eat fewer meals together than higher income and non-minority families (Hammons \& Fiese, 2011; Melgar-Quinonez \& Kaiser, 2004), few studies have assessed the association between family eating and child weight within these populations.

Much of the literature on family food behaviors examines parental restriction of or pressure to eat certain foods. These intrusive practices are posited to reflect an authoritarian feeding style (Patrick, Nicklas, Hughes, \& Morales, 2005), and have been associated with heavier weight among young children in predominately white samples (Faith, Scanlon, Birch, 
Francis, \& Sherry, 2004; Ventura \& Birch, 2008). In contrast, studies of low-income, minority families fail to find this association (Hughes, Power, Fisher, Mueller, \& Nicklas, 2005; Hughes et al., 2006; Larios, Ayala, Arredondo, Baquero, \& Elder, 2009; MelgarQuinonez \& Kaiser, 2004). Socioeconomic variation in the effects of these intrusive practices has prompted a shift toward identifying other ways parents shape their children's consumption that may better explain child weight in low-income and minority families (Chaidez \& Kaiser, 2011).

Allowing the child to control food choices is one parenting practice that may explain weight variation in low-income families. Afternoon snacking has been found to be especially prevalent among Hispanic toddlers (Ziegler et al., 2006), while allowing children to freely snack in between meals corresponded to healthier child weight among low-income, Mexican American preschoolers (Melgar-Quinonez \& Kaiser, 2004). A related study found that greater child control of food intake corresponded to higher intake of fruits and vegetables among preschoolers (Kroller \& Warschburger, 2008). In contrast, greater child control over food intake increased consumption of unhealthy foods among a sample of low-income Hispanic toddlers; however, this study included intrusive parental practices (e.g., offering the child sweetened beverages) as indicating greater child control of food (Chaidez \& Kaiser, 2011). To date, the relationship between non-intrusive parental practices around the child's opportunity to control food choices and child weight remains an under-investigated line of inquiry, especially as to potential protective effects against child overweight in lowincome families.

Maternal efforts to provide consistency in eating routines and schedules have been hypothesized to foster healthy eating habits among children (Fischer \& Silverman, 2007). While such practices have received limited empirical attention, recent research highlights the need for further study. One study examined primarily low-income, non-Hispanic white families and found that mothers of healthy weight preschoolers were more likely to provide greater structure during feeding, such as established routines, as compared to mothers of overweight preschoolers, though this association disappeared after adjusting for income (Baughcum et al., 2001). A second study linked consistent mealtime schedules to reduced grazing between meals and more positive mealtime environments in a sample of 2 to 6 year old children in predominately white families (Berlin, Davies, Silverman, \& Rudolph, 2011).

Other family food behaviors that have been found to be more prevalent among low-income families may contribute to child overweight in this population. For example, low-income families often report difficulty managing their food dollars (Ziegler et al., 2006). To date, skills associated with managing food resources have received limited attention as a correlate of child weight. Low-income families are more likely to allow their children to eat in front of the television (Hammons \& Fiese, 2011) and are more likely to live in neighborhoods with higher concentrations of fast food restaurants (Reidpath, Burns, Garrard, Mahoney \& Townsend, 2008) than higher income families. Television watching while eating has been associated with heavier BMI $z$ scores in older children (MacFarlane, Cleland, Crawford, Campbell, \& Timperio, 2009), and with increased consumption of unhealthy foods among middle school children (Coon, Goldberg, Rogers, \& Tucker, 2001). Consumption of fast food among Mexican-American families (Duerksen et al., 2007) and older children 
(MacFarlane et al., 2009) has been linked to child overweight, though few studies have examined whether such practices are associated with variation in child weight among lowincome families.

\section{Maternal depression}

One major barrier low-income families may face in the struggle to provide a healthy family food environment is maternal depression. As posited by Conger and others, the stress associated with poverty impacts maternal mental health which, in turn, inhibits the use of competent and responsive parenting behaviors, with negative effects on children (Conger \& Elder, 1994; Conger et al., 2002). In support of this theory, rates of depression are substantially higher among low-income women (Ertel et al., 2011) and maternal depression has been found to exert strong and long-lasting effects on child behavior and cognition (Letourneau, Salmani, \& Duffett-Leger, 2010; Sobolewski \& Amato, 2005). Findings are mixed, however, as to the relationship between maternal depression a nd child weight (Bronte-Tinkew, Zaslow, Capps, Horowitz, \& McNamara, 2007; Lytle et al., 2011) and few studies have investigated this association in preschool age children. One national study of 310 year old low-income children found that cumulative maternal stressors, including maternal depression, predicted a greater likelihood of overweight among food secure children as compared to food insecure children (Gundersen et al., 2008). Further, depression has been associated with more authoritarian and distant feeding styles among low-income mothers of infants (Hurley, Black, Papas, \& Caufield, 2008), and reduced use of positive family meal practices, such as eating meals as a family or not allowing the child to watch TV during meals among primarily white, well-educated parents of youth (Lytle et al., 2011). Such findings support the proposition that depression may inhibit low-income parents from utilizing family food behaviors that foster healthy weight among young children (McCurdy, Gorman \&, Metallinos-Katsaras, 2010), though research testing this hypothesis has been limited.

The current study addresses these gaps in the empirical literature by examining associations between family food behaviors, including family mealtime practices and food resource management skills, maternal depression, and child weight in a sample of ethnically diverse, low-income families. The following hypotheses were tested: 1) maternal depression will correspond to less involved and more disorganized family food behaviors; 2) more involved and organized family food behaviors will be associated with healthier child weights; and 3) maternal depression will reduce the association between more involved and organized family food behaviors and healthier child weights.

\section{METHODS}

\section{Study Design and Subjects}

Between October 2009 and May 2011, a convenience sample of 164 mothers of 2-5 year old children were recruited from seven day care centers and a Supplemental Nutrition Assistance Program outreach project located in two low-income urban neighborhoods in Rhode Island. Research staff visited the centers and the outreach project to recruit parents during peak parent flow times. Women picking up children were asked to participate in a 
study on the challenges of feeding their children healthy food. To be included in the study, women had to be the primary caregiver of the child, speak English or Spanish, and have a child between 25 to 60 months of age. If a mother had more than one preschool-aged child, the target child was chosen by coin toss to ensure a random selection.

After obtaining informed consent, trained bilingual research staff orally administered the self-report measures to the mothers, using English or Spanish versions as appropriate. The measures took 30-40 minutes to complete. Participating mothers were provided with $\$ 20$ for their study involvement. The Institutional Review Board at the University of Rhode Island approved these procedures. A priori power analyses indicated that 150 participants were sufficient to detect moderate $(r=.15)$ regression effects with up to 12 predictor variables (Faul, Erdfelder, Lang, \& Buchner, 2007). To achieve this size, over 200 mothers were approached by researchers with 172 mothers agreeing to participate and completing the surveys. Eight participants were excluded because their child could not be measured $(n=7)$ or had not reached 25 months of age $(n=1)$, for a final sample size of 164 children ages 25 to 60 months, and their mothers.

\section{Anthropometry}

Four trained interviewers (inter-rater reliabilities $>.92$ ) measured child height (to nearest 0.1 $\mathrm{cm}$ ) with a portable SECA 213 stadiometer (SECA, Hanover, MD) and weight (to nearest $0.1 \mathrm{~kg}$ ) with a portable digital scale (SECA 876; SECA; Hanover, MD) on site in a private room (e.g., director's office). Children were measured twice and the average score was used to calculate child body mass index (BMI), defined as weight $(\mathrm{kg}) /$ height $(\mathrm{m})$ squared (National Center for Health Statistics, 2004). BMI-for-age $z$-scores and percentiles were calculated from Centers for Disease Control and Prevention reference data (Centers for Disease Control and Prevention, 2000). Standard child weight cutoffs were used: 1) healthy weight $=\geq 5^{\text {th }}$ percentile and $<85^{\text {th }}$ percentile; 2 ) overweight $=\geq$ the $85^{\text {th }}$ percentile and $<$ the $95^{\text {th }}$ percentile; and 3 ) obese $=\geq 95^{\text {th }}$ percentile (American Academy of Pediatrics, 2003). To maximize sample size, we combined the overweight $(n=28)$ and obese $(n=26)$ categories into one category: overweight $=\geq 85^{\text {th }}$ percentile. For the remainder of the article, the term "overweight" is used to refer to this group. There were no underweight children (< $5^{\text {th }}$ percentile) in the sample. Maternal BMIs were calculated from maternal self-report of height and weight as no adequate private space was available for measuring mothers during pick-up and drop-off times at the centers.

\section{Family Food Behaviors}

Family Mealtime Practices. The 20 item Family Food Behavior Survey (FFBS) assesses family mealtime practices with a 5-point Likert-scale, ranging from 0 (never true) to 4 (always true). A pilot study with an ethnically diverse sample identified four scales with acceptable reliabilities (McCurdy \& Gorman, 2010). Two of the 4 scales were associated with child overweight: maternal control of child eating routines, e.g., my child has a regular snack and mealtime routine (5 items), and maternal presence when child eats, e.g., I sit down with child when s/he eats ( 5 items). In the current study, only these 2 scales achieved acceptable internal reliabilities, with Cronbach's a for maternal control and maternal presence of .73 and .72 , respectively. Factor analysis using varimax rotation with the 
remaining 10 FFBS items confirmed two additional factors: Negative Mealtime Practices (4 items, $a=.73$ ) consisting of my child eats and watches TV at same time, my child wanders during meals, my child and I watch TV while eating, and, my child and I eat at fast food restaurants; and Child Control of Snacking ( 3 items, $a=.79$ ) consisting of I allow child to snack whenever child wants; I decide how many snacks my child should have (reverse coded), and child eats snacks whenever child wants. On all 4 FFBS scales, higher scores indicated greater frequency of those behaviors.

Food resource management skills were assessed with a 4 item scale, drawn from focus group studies of low-income families where families reported difficulties with or desire to learn more about keeping within a budget, paying bills, feeding the family (Hoisington, Shultz, \& Butkus, 2002; Kempson, Keenan, Sadani, \& Adler, 2003), and making nutritious meals (Hoisington et al.). Parents rated their food resource management skills (e.g., can manage bills, able to keep within family budget, can stretch groceries for a month, can make well-balanced meals) on a five point, Likert scale $(1=$ strongly disagree to $5=$ strongly agree). Factor analysis indicated that all 4 items loaded onto the same scale (all coefficients $>.55$ ), providing evidence for construct validity. These items were summed to create the food resource management skills scale $(\alpha=.69)$. Higher scores indicated better food resource management skills.

\section{Maternal Depressive Symptoms}

Participants completed the Center for Epidemiologic Studies Depression Scale (CES-D; Radloff, 1977), a 20 item, self-report instrument that screens for the presence of depressive symptoms during the previous week. Participants responded to 20 statements on a 4-point rating scale $(0=$ rarely to $3=$ most $/$ all of the time $)$. This screening measure has achieved high internal consistency for both the English $(a>.84)$ and Spanish $(a=.90)$ versions (Hann, Winter, \& Jacobsen, 1999; Gonzalez, Stewart, Ritter, \& Lorig, 1995). Scores on the CES-D range from 0 to 60 , with higher scores indicating more depressive symptoms. Scores of 16 or higher may indicate the need for clinical assessment for depression (Weissman, Sholomskas, Pottenger, Prusoff, \& Locke, 1977).

\section{Covariates}

Participants completed a family form assessing demographic and health characteristics of the child, parent, and family. Child items included age in months, gender, and ever breastfed. Parent and family variables included household size, partner/marital status, maternal age, years mother attended school; whether the mother was employed; use of government assistance programs, maternal ethnicity/race, and whether Spanish was the only language spoken in the home. Because of small numbers of non-Hispanic whites $(n=21)$, non-Hispanic blacks $(n=38)$, and non-Hispanic other race $(n=15)$, relative to Hispanics ( $n$ =90), subjects are grouped by Hispanic ethnicity (Hispanic or non-Hispanic). Monthly household income range, collected in increments of $\$ 500$, was collapsed into 3 equivalent sized groupings ( $<\$ 1,000 ; \$ 1,001-\$ 1,500 ;>\$ 1,500)$. Food security status in the previous 12 months was measured with the USDA 18-item Food Security Core Module and classified as follows: Household food secure $=<3$ affirmative responses, and household food insecure $=\geq 3$ affirmative responses (Bickel, Nord, Price, Hamilton \& Cook, 2000). The FSCM 
includes 8 child-related items that assess child food security status within the household (e.g., We couldn't feed the children a balanced meal). Child food insecurity (CFI) is defined as positive responses to 2 or more child-related items (Casey et al., 2006).

\section{Statistical Analysis}

Data were analyzed with SPSS (v. 19, 2010, IBM, Armonk, NY). Preliminary analyses assessed variables for normality, completeness, and multicollinearity. Chi-square analyses and independent groups $t$-tests were used to identify significant $(P<.05)$ covariates of child weight. All multivariate analyses adjusted for significant covariates. To determine if the recruitment strategy resulted in nested data (i.e., families recruited from one site sharing unmeasured characteristics that differed from families recruited from other sites), SPSS Linear Mixed Models with random effects was used to fit the data to a two-level hierarchical model (Murray, Varnell, \& Blitstein, 2004). The model showed little variation at the site level, supporting the use of regression models. The outcome, child weight, was examined with two indicators: 1) a dichotomous outcome to capture current correlates of child overweight; and, 2) a continuous measure (child BMI $z$ scores) to detect weaker yet important correlates of shifts in the sample's weight distribution.

The associations between maternal depressive symptoms and the family food behavior scales (Hypothesis 1) were tested with SPSS General Linear Model procedure for multiple dependent variables. Hierarchical multivariate regression analyses were used to test the relationships between family food behavior and maternal depressive symptoms with child weight. The family food behavior scales and CES-D scores were centered prior to entry in the regression models (Fairchild \& MacKinnon, 2009). In the hierarchical regression models, significant covariates were entered in the first step. To create a parsimonious model, forward entry of significant family food behavior scales occurred in the second step (Hypothesis 2); Step 3 entered maternal CES-D scores to the equation, and Step 4 entered interaction terms between CES-D scores and any significant family food behavior scale (Hypothesis 3). For child BMI $z$ scores, the $b$ coefficients and explained variance (Adjusted $R^{2}$ ) were examined for significance. For child overweight status, adjusted odds ratios (AOR) and confidence intervals (CI) were examined. For all multivariate analyses, significance was set at $P<.05$. The final regression results exclude respondents with any missing data $(n=$ $10)$, though the results did not vary when mean substitution was used.

\section{RESULTS}

\section{Descriptive analyses}

Table 1 displays the characteristics of the sample. The majority of mothers were single (69.8\%) with monthly household incomes of less than $\$ 1,500$ (60.7\%). Just over half of the sample was of Hispanic ethnicity (54.9\%), and $25 \%$ of families exclusively spoke Spanish in the home. Nearly all families (96.3\%) received some form of government assistance, with over 80\% participating in SNAP and/or WIC. Mean maternal BMI was $29.2(S D=7.6)$, with $66.1 \%$ of mothers meeting the classification of overweight or obese (BMI $\geq 25$ ). Food insecurity was prevalent in this sample with $42.7 \%$ of mothers reporting household food insecurity and $24.4 \%$ reporting child food insecurity. 
One-third of the children were overweight (17.1\%) or obese (15.9\%). Three sociodemographic variables had significant bivariate associations with the child weight indicators. As shown in Table 1, $\chi^{2}$ analyses demonstrated that healthy weight children were more likely to have mothers with lower BMIs $(P<.05)$ and to live in households with monthly incomes over $\$ 1,500(P<.05)$ as compared to overweight children. Independent samples $t$-tests (not shown) revealed significantly higher $(t=2.01, P=.04)$ BMI $z$ scores ( $M$ $=.78, S E=.11)$ for Hispanic children $(n=90)$ as compared to BMI $z$ scores $(M=.45, S E=$. $12)$ for non-Hispanic children $(n=74)$. No other parent or child characteristic, including household or child food security status, was significantly associated with child weight. In addition, maternal depressive symptoms were not significantly associated with child BMI $z$ scores or child weight status. All multivariate analyses adjusted for maternal BMI, Hispa nic ethnicity, and monthly household income.

Table 2 presents the mean, standard deviation, variance, and range for the independent variables of interest. Overall, 24\% of mothers had high levels of depressive symptoms, defined as scores of 16 or more on the CES-D. In terms of family mealtime practices, the typical mother reported often being present when the child ate, and sometimes or often providing consistency in the child's eating routines. In contrast, mothers reported relatively infrequent use of negative mealtime practices and allowing the child to control snacking. The average parent reported positive perceptions of her food resource management skills.

\section{Hypothesis testing}

As predicted in Hypothesis 1, the multivariate general linear model results revealed that maternal depression scores were significantly associated with the family food behavior scales, Wilks's lambda $=0.89, F(5,147)=3.47, P=.005$, adjusting for maternal BMI, Hispanic ethnicity, and household income level. Parameter estimates indicated that greater depressive symptoms correlated with lower scores on maternal presence when the child ate $(t=-1.99, P=.049)$ and maternal control of child's eating routines $(t=-2.29, P=.023)$, and with higher scores on negative mealtime practices $(t=2.47, P=.015)$ and child control of snacking patterns $(t=2.31, P=.022)$. CES-D scores had the most robust association with food resource management skills $(t=-3.07, P=.003)$, indicating that greater maternal depressive symptoms correlated with fewer food resource management skills.

The multiple regression analyses provided some support for the second hypothesis that family food behavior would be associated with child weight. In Table 3, maternal presence when the child ate met the significance criterion for inclusion as a predictor of child BMI $z$ scores $\left(\Delta r^{2}=.026, \Delta F=4.38, P=.039\right.$ ), after adjusting for income level, Hispanic ethnicity, and maternal BMI. As shown in Step 2, the inverse beta coefficient $(\beta=-.163)$ indicates that higher maternal presence corresponded to lower child BMI z scores. The addition of CES-D scores in Step 3 and the interaction term for CES-D scores with the maternal presence scale in Step 4 did not significantly improve the adjusted $R^{2}$ nor were they significantly associated with child BMI $z$ scores.

A different pattern emerged in the logistic regression analysis of child weight status (Table 4). After adjusting for demographic differences, food resource management skills was the only family food behavior to significantly explain child weight status. In the final model, 
higher scores on the food resource management skills scale corresponded to a reduced odds of child overweight $(\mathrm{AOR}=0.82,95 \% \mathrm{CI}=0.72-0.95)$. Similar to the analysis of BMI $z$ scores, the addition of maternal depression in Step 3 and the interaction of CES-D scores with food resource management skills in Step 4 did not significantly alter the likelihood of child overweight.

\section{DISCUSSION}

This study sought to explain variation in child weight among low-income families of young children by testing the relationships between family food behaviors and maternal depression with child weight. Of the family food behaviors examined, greater maternal presence whenever the child ate and better food resource management skills were significantly associated with healthier child weights among this sample of $2-5$ year old children living in low-income families. The results also indicated that maternal depression was significantly related to all family food behaviors. However, maternal depressive symptoms did not alter the relationship between these behaviors and the child weight indicators.

In terms of family mealtime practices, these results support and extend research noting that family meals are associated with healthier weight of preschool aged children (Valdes et al., 2012). The study's multi-item scale assessed maternal presence whenever a child ate, not just at meals, thereby providing a more accurate assessment of the eating environment for preschool children. While maternal presence significantly explained child BMI z scores, it was not associated with child overweight status. One plausible explanation for this discrepancy arises from the study's use of cross-sectional data as factors associated with BMI $z$ scores in young children, such as maternal presence when the child eats, may be meaningful predictors of future child weight status even when not associated with current weight status. In support of this hypothesis, research has shown that preschool children with elevated BMIs falling in the healthy weight range (i.e., less than $85^{\text {th }}$ percentile, but above the $50^{\text {th }}$ percentile) have increased odds of being overweight at age 12 (Nader et al., 2006). Our findings also are consistent with research on parental modeling of healthy eating habits, which has been associated with healthier diets among children (c.f., Patrick \& Nicklas, 2005) but did not predict short-term changes in preschoolers' weight status in a middle class sample (Gregory, Paxton, \& Brozovic, 2010). While parental modeling of healthy eating practices may explain the positive association between maternal presence when the child eats and child BMI $z$ scores, the current study did not assess modeling or maternal eating practices. Observational data are needed to fully unpack the processes that connect eating with a parent to child weight.

Maternal control over child eating routines was not associated with child weight indictors in this low-income, ethnically diverse sample. This result is consistent with research assessing a similar construct among low-income, white families (Baughcum et al., 2001), though the reliability of the current study measure is significant higher $(\alpha=.73)$ than that used in Baughcum's validation study $(\alpha=.37)$. Given that establishing consistency in eating routines has been identified as a challenge faced by low-income mothers (Child Trends, 2003), these findings may reflect that low-income families are constrained in their ability to provide consistent and predictable routines. However, the consistent eating routines scale 
had sufficient variation and the average mother reported that she sometimes or often provided consistency in mealtime routines. Thus, while intervention efforts often seek to help parents provide consistent and predictable eating routines for children (Berlin et al., 2009), such efforts may not be enough to promote healthy child weight among low-income families.

Similarly, child control of snacking was not significantly related to child weight. These results depart from Melgar-Quinonez and Kaiser's (2008) finding that taking food between meals corresponded to lower weight among low-income, Mexican American preschool children. Ethnic and acculturation differences may explain these divergent findings. The current study sample included a large portion of non-Hispanic children (45\%), and both Hispanic and non-Hispanic families reported similar and relatively low use of this practice. In contrast, $81 \%$ of Mexican American parents in the earlier study allowed children to take food between meals. Further, $66 \%$ of the Mexican-American parents identified as Spanish dominant (Melgar-Quinonez \& Kaiser, 2008). Though measured somewhat differently, only $25 \%$ of parents in the current study reported exclusive use of Spanish in the home. Finally, Hispanic families in the current study most likely included other Hispanic groups beyond Mexican-Americans, as Rhode Island is home to large concentrations of families of Puerto Rican and Dominican origin (Office of Minority Health, 2011). Thus, acculturation and culture may impact the use or effect of this mealtime practice in unknown ways. Future research in low-income Hispanic populations should collect maternal country of birth and family origin to examine these possibilities.

Negative mealtime practices, including watching TV while eating and eating at fast food restaurants, did not significantly influence either child weight indicator. Such relationships have been found in previous studies (Coon et al., 2001; Duerkson et al., 2007; MacFarlane et al., 2009), though some of this research used older and more economically advantaged samples (Coon et al., 2001; MacFarlane et al., 2009), and none assessed whether the parent was present when the child ate. Indeed, the bulk of studies investigating parental feeding styles and mealtime practices did not assess eating meals as a family or with a parent (e.g., Hendy et al., 2009; Kroller \& Warshburger, 2008; Melgar-Quinonez \& Kaiser, 2004; Patrick et al., 2005). Thus, among low-income families, caregiver presence whenever the child eats may be of particular importance.

This study is one of the few to quantify and assess the relationship between parental assessments of food resource management skills and child weight. Though in need of further validation, low-income parents reporting higher ratings on the food resource management skills scale were less likely to have overweight children than parents with lower ratings. A recent study linking higher self-competence in planning meals to greater use of home-based as compared to take away food strategies among high income parents (Morin, Demers, Turcotte, \& Mongeau, 2013), suggests one pathway between better food management skills and healthier child weight. Low-income parents who can better manage their food resources may be more likely to serve meals at home, which typically have lower fat content than take away meals (Lachat et al., 2012). The positive results from a brief nutrition education intervention provided to low-income minority women, which increased participants' beliefs that they could stretch their limited f ood dollars and provide nutritious meals (Rustard \& 
Smith, 2012), shows the potential for nutrition education efforts to enhance competence in food resource management skills, especially ways to purchase nutritious foods with limited resources and methods to prepare healthy foods.

It is possible that maternal education explains the connection between food resource management skills and healthier weight among children, if more highly educated mothers have greater knowledge about food resource management and healthy nutrition for their children. However, post-hoc analyses revealed no significant correlation between years of education and scores on the food resource management scale $(p>.10)$, nor was maternal education significantly correlated with the child weight indicators when added as a covariate to the regression equations. As the current study relied on cross-sectional data, it also is unclear whether food resource management skills affected child weight status or whether child weight status influenced food resource management skills. The fact that food resource management skills were not associated with current child BMI $z$ scores is consistent with the latter possibility that parental perceptions of their ability to keep within a budget, stretch food supplies to last the month, and make nutritious meals may be in response to their child's weight status or concern about their child's weight (Ventura \& Birch, 2008). Longitudinal data are needed to discern the direction of this relationship.

In this study, higher maternal depression scores were associated with less involved and more disorganized family mealtime practices. In particular, depression was significantly associated with lower levels of maternal control over child eating routines, lower maternal presence when the child ate, greater child choice over snacking, and more negative mealtime practices. Other studies have reported similar associations between maternal depression and parenting quality (Letourneau, Salmani, \& Duffett-Leger, 2010) and family mealtime practices with youth (Lytle et al., 2011). Higher depression scores also corresponded to more negative ratings of food resource management skills. While previous research has connected depression to negative assessments of competence in other areas of parenting (Sanders \& Woolley, 2005; Silver, Heneghan, Bauman, \& Stein, 2006), this study adds to the literature by finding a similar relationship between maternal depression and parental beliefs about their ability to manage food supplies in the household. Though cross-sectional, the results are in line with family stress theory, which predicts that diminished maternal mental health will inhibit the use of responsive parenting (Conger et al., 2002), and suggest that identifying and alleviating maternal depressive symptoms may be one promising method for enhancing the family food environment. Future observational research is needed to determine if and how maternal depressive symptoms impact actual food behaviors, in order to devise appropriate intervention strategies.

Despite these relationships, current maternal depressive symptoms did not significantly alter the associations between family food behaviors and child weight, nor did depressive symptoms directly influence child weight. While unexpected, this finding may reflect that chronic depression (Wojcicki et al., 2011) is more likely to influence child weight than current depressive symptoms. Indeed, a recent review of prospective studies found that chronic depression predicted child overweight, but episodic depression did not (Lampard, Franckle, \& Davidson, 2014). Further, other individual stressors, such as those related to family structure (Gibson et al., 2007; Gundersen et al., 2008), or cumulative measures of 
stress (Gundersen et al., 2008) may better explain child weight outcomes, although more research is needed to examine these relationships among low-income preschool-aged children.

Of note, household and child food insecurity were not associated with child overweight or BMI $z$ scores. As a national study found that food security status interacted with maternal stressors to increase the likelihood of overweight among low-income children (Gundersen et al., 2008), post hoc analyses were conducted to examine food security status and its interaction with maternal depression in the regression equations. The regression results were essentially unchanged and neither variable was significant related to the child weight indictors. In the current study, child obesity (BMI $\geq 95^{\text {th }}$ percentile) did occur somewhat more frequently in food insecure as compared to food secure households $(p<.10)$, but the small number of obese children in the sample $(n=26)$ precluded the use of this outcome in the multivariate analyses. Given the sample size and current debate over this relationship (Metallinos-Katsaras, Sherry \& Kallio, 2009), this lack of association should be interpreted with caution.

Several limitations to the study need to be acknowledged. First, the use of maternal selfreport for both depression and family food behaviors may explain some of the association between these measures. Maternal BMIs also were calculated with self-report data which may produce underestimates of BMI (Jeffery et al., 2008) and thus bias the findings in unknown ways. The study relied on cross-sectional data, thereby preventing inferences about causality. Because study participants came from low-income, urban neighborhoods in Rhode Island, these findings may not apply to other low-income populations. Though $a$ priori power analyses indicated that the sample size was sufficient for hypothesis testing, the relatively small sample may have limited the detection of other important effects. As with many studies of parenting, data were collected only from the mother, even though $42 \%$ of the sample had a partner or spouse. Future studies should include observational data on parent and child behavior during meals and snacks; assess the contributions of other caregivers in the household; and, measure parental pressure to eat (Scaglioni, Arrizza, Vecchi \& Tedeschi 2011), parental restriction of unhealthy foods (Larios et al., 2009), and child nutritional intake, to better capture the full impact of family food behaviors and parental depression on child weight.

\section{CONCLUSIONS}

The study found that maternal presence when a child eats and better food resource management skills were associated with healthier child weight among preschool children. Greater maternal depressive symptoms corresponded to negative family food behaviors, but were not associated with child weight. These findings suggest the need to pay greater attention to the caregiver's presence whenever a child eats, not just at meals, as one potential path to healthier child weight. Food resource management skills may be a protective factor for low-income families and should be a focus of future research. Though preliminary, the findings are of practical interest as food resource management skills are potentially modifiable behaviors that could be targeted by intervention efforts and such skills may be particularly helpful for low-income families. 


\section{Acknowledgments}

The authors would like to Kristen Guertin and Stephen Favasuli for their assistance with data collection and management. This research was supported by award number RO3HD05524 from the Eunice Kennedy Shriver National Institute of Child Health and Human Development. The content is solely the responsibility of the authors and does not necessarily represent the official views of the Eunice Kennedy Shriver National Institute of Child Health and Human Development or the National Institutes of Health.

\section{References}

American Academy of Pediatrics. Prevention of pediatric overweight and obesity. Pediatrics. 2003; 112:424-430. [PubMed: 12897303]

Baughcum A, Powers S, Johnson S, Chamberlin L, Deeks C, Jain A, Whitaker R. Maternal feeding practices and beliefs and their relationships to overweight in early childhood. Developmental and Behavioral Pediatrics. 2001; 22:391-408.

Berlin K, Davies WH, Silverman A, Rudolph C. Assessing family-based feeding strategies, strengths, and mealtime structure with the feeding strategies questionnaire. Journal of Pediatric Psychology. 2011; 36:586-595. [PubMed: 19995867]

Bickel, G.; Nord, M.; Price, C.; Hamilton, W.; Cook, J. Guide to measuring household security, revised 2000. Washington, DC: United States Department of Agriculture, Food and Nutrition Service; 2000.

Bronte-Tinkew J, Zaslow M, Capps R, Horowitz A, McNamara J. Food insecurity works through depression, parenting, and infant feeding to influence overweight and health in toddlers. Journal of Nutrition. 2007; 137:2160-2165. [PubMed: 17709458]

Casey P, Goolsby S, Berkowitz C, Frank D, Cook J, Cutts D, Black M, Zaldivar M, Levenson S, Heeren T, Meyers A. the Children's Sentinel Nutritional Assessment Program Study Group. Maternal depression, changing public assistance status, food security, and child health status. Pediatrics. 2004; 113:298-304. [PubMed: 14754941]

Casey P, Simpson P, Gossett J, Bogle M, Champagne C, Connell C, Harsha D, McCabe-Sellers B, Robbins J, Stuff J, Weber J. The association of child and household food insecurity with childhood overweight status. Pediatrics. 2006; 118:e1406-e1413. [PubMed: 17079542]

Centers for Disease Control and Prevention. [Accessed: May 30, 2011] CDC growth charts: United States. 2000. 2000. http://www.cdc.gov/growthcharts/.

Chaidez V, Kaiser L. Validation of an instrument to assess toddler feeding practices of Latino mothers. Appetite. 2011; 57:229-236. [PubMed: 21600943]

Child Trends. Regular bedtime and mealtime. 2003 Downloaded on March, 152010 from http:// www.childtrendsdatabank.org/archivepgs/91.htm.

Conger, R.; Elder, G, Jr. Families in troubled times: Adapting to change in rural America. Hillsdale, NJ: Aldine; 1994.

Conger R, Wallace L, Sun Y, Simons R, McLoyd V, Brody G. Economic pressure in African American families: A replication and extension of the family stress model. Developmental Psychology. 2002; 38:179-193. [PubMed: 11881755]

Coon K, Goldberg J, Rogers B, Tucker K. Relationships between use of television during meals and children's food consumption patterns. Pediatrics. 2001; 107:e7. [PubMed: 11134471]

Dalenius, K.; Borland, E.; Smith, B.; Polhamus, B.; Grummer-Strawn, L. Pediatric Nutrition Surveillance 2010 Report. Atlanta: United States Department of Health and Human Services, Centers for Disease Control and Prevention; 2012.

Dennis CL, McQueen K. The relationship between infant-feeding outcomes and postpartum depression: A qualitative systematic review. Pediatrics. 2009; 123:e736-e761. [PubMed: 19336362]

Dennison B, Erb T, Jenkins P. Television viewing and television in bedroom associated with overweight risk among low-income preschool children. Pediatrics. 2002; 109:1028-1035. [PubMed: 12042539] 
Duerksen SC, Elder JP, Arredondo EM, Ayala GX, Slymen DJ, Campbell NR, Baquero B. Family restaurant choices are associated with child and adult overweight status in Mexican-American families. Journal of the American Dietetic Association. 2007; 107:849-853. [PubMed: 17467384]

Edmunds L, Woelfel ML, Dennison B, Stratton H, Pruzek R, Abusabha R. Overweight trends among children enrolled in the New York State Special Supplemental Nutrition Program for Women, Infants, and Children. Journal of the American Association. 2006; 106:113-117.

Ertel K, Rich-Edwards J, Koenen K. Maternal depression in the Unites States: Nationally representative rates and risks. Journal of Women's Health. 2011; 11:1609-1617.

Fairchild A, MacKinnon D. A general model for testing mediation and moderation effects. Prevention Science. 2009; 10:87-99. [PubMed: 19003535]

Faith M, Scanlon K, Birch L, Francis L, Sherry B. Parent-child feeding strategies and their relationships to child eating and weight status. Obesity Research. 2004; 12:1711-1722. [PubMed: 15601964]

Faul F, Erdfelder E, Lang AG, Buchner A. G*Power 3: A flexible statistical power analysis program for the social, behavioral, and biomedical sciences. Behavioral Research Methods. 2007; 39:175191.

Fischer E, Silverman A. Behavioral conceptualization, assessment, and treatment of pediatric feeding disorders. Seminar in Speech and Language. 2007; 28:223-231.

Flores G, Tomany-Korman S, Olson L. Does disadvantage start at home? Racial and ethnic disparities in health-related early childhood home routines and safety practices. Archives of Pediatric Adolescent Medicine. 2005; 159:158-165.

Gable S, Chang Y, Krull J. Television watching and frequency of family meals are predictive of overweight onset and persistence in a national sample of school-age children. Journal of the American Dietetic Association. 2007; 107:53-61. [PubMed: 17197271]

Gonzalez V, Stewart A, Ritter P, Lorig K. Translation and validation of arthritis outcome measures into Spanish. Arthritis and Rheumatism. 1995; 38:1429-1446. [PubMed: 7575693]

Gregory J, Paxton S, Brozovic A. Maternal feeding practices, child eating behavior and body mass index in preschool-aged children: a prospective analysis. International Journal of Behavioral Nutrition and Physical Activity. 2010; 7:55. [PubMed: 20579397]

Gundersen C, Lohman b, Garasky S, Stewart S, Eisenmann J. Food security, maternal stressors, and overweight among low-income US children: Results from the National Health and Nutrition Examination Survey (1999-2002). Pediatrics. 2008; 122:e529-e540. [PubMed: 18762488]

Hammons J, Fiese B. Is frequency of shared family meals related to the nutritional health of children and adolescents? Pediatrics. 2011; 127:e1565-e1574. [PubMed: 21536618]

Hann D, Winter K, Jacobsen P. Measurement of depressive symptoms in cancer patients: Evaluation of the Center for Epidemiological Studies - Depression Scale (CES-D). Journal of Psychosomatic Research. 1999; 46:437-443. [PubMed: 10404478]

Hendy J, Williams K, Camise T, Eckman N, Hedemann A. The Parent Mealtime Action Scale (PMAS): Development and association with children's diet and weight. Appetite. 2009; 52:328 339. [PubMed: 19059292]

Hersey J, Anliker J, Miller C, Mullis R, Daugherty S, Das S, Bray C, Dennee P, Sigman-Grant M, Thomas HO. Food shopping practices are associated with dietary quality in low-income households. Journal of Nutrition Education. 2001; 33:S16-S26. [PubMed: 12857541]

Hoisington A, Shultz J, Butkus S. Coping strategies and nutrition education needs among food pantry users. Journal of Nutrition Education and Behavior. 2002; 34:326-333. [PubMed: 12556271]

Hughes S, Anderson C, Power T, Micheli N, Jaramillo S, Nicklas T. Measuring feeding in low-income African-American and Hispanic parents. Appetite. 2006; 46:215-223. [PubMed: 16504340]

Hughes S, Power R, Fisher J, Mueller S, Nicklas T. Revisiting a neglected construct: Parenting styles in a child-feeding context. Appetite. 2005; 44:83-92. [PubMed: 15604035]

Hurley K, Black M, Papas M, Caufield L. Maternal symptoms of stress, depression, and anxiety are related to nonresponsive feeding styles in a statewide sample of WIC participants. Journal of Nutrition. 2008; 138:799-805. [PubMed: 18356338] 
Jeffery R, Finch E, Linde J, Simon G, Ludman E, Operskalski B, Rohde P, Ichikawa L. Does clinical depression affect the accuracy of self-reported height and weight in obese women? Obesity. 2008; 16(2):473-475. [PubMed: 18239662]

Kempson K, Keenan DP, Sadani PS, Adler A. Maintaining food sufficiency: Coping strategies identified by limited-resource individuals versus nutrition educators. Journal of Nutritional Education and Behavior. 2003; 35:179-188.

Kroller K, Warschburger P. Associations between maternal feeding style and food intake of children with a higher risk for overweight. Appetite. 2008; 5:166-172. [PubMed: 18342396]

Lachat C, Nago E, Verstraeten R, Roberfroid D, Van Camp J, Kolsteren P. Eating out of home and its association with dietary intake: a systematic review of the evidence. Obesity Reviews. 2012; 13:329-346. [PubMed: 22106948]

Lampard A, Franckle R, Davidson K. Maternal depression and childhood obesity: A systematic review. Preventive Medicine. 2014; 59:60-67. [PubMed: 24291685]

Larios S, Ayala G, Arredondo E, Baquero B, Elder J. Development and validation of a scale to measure Latino parenting strategies related to children's obesogenic behaviors. The parenting strategies for eating and activity scale (PEAS). Appetite. 2009; 52:166-172. [PubMed: 18845197]

Letourneau N, Salmani M, Duffett-Leger L. Maternal depressive symptoms and parenting of children from birth to 12 years. Western Journal of Nursing Research, 2010. 2010; 32:662-685.

Lin B-H, Huang C, French S. Factors associated with women's and children's body mass indices and income status. International Journal of Obesity. 2004; 28:536-542. [PubMed: 14770199]

Lytle L, Hearst M, Fulkerson J, Murray D, Martinson B, Klein E, Pasch K, Samuelson A. Examining the relationships between family meal practices, family strengths, and the weight of youth in the family. Annals of Behavioral Medicine. 2011; 41:353-362. [PubMed: 21136225]

MacFarlane A, Cleland V, Crawford D, Campbell K, Timperio A. Longitudinal examination of family food environment and weight status among children. International Journal of Pediatric Obesity. 2009; 4:343-352. [PubMed: 19922051]

McCurdy K, Gorman K, Metallinos-Katsaras E. From poverty to food insecurity and child overweight: A family stress approach. Child Development Perspectives. 2010; 4:144-151.

McCurdy K, Gorman K. Measuring family food environments in diverse families with young children. Appetite. 2010; 54:615-618. [PubMed: 20227449]

Melgar-Quinonez HR, Kaiser LL. Relationship of child-feeding practices to overweight in low-income Mexican-American preschool-aged children. Journal of the American Dietetic Association. 2004; 104:1110-1119. [PubMed: 15215770]

Metallinos-Katsaras E, Sherry B, Kallio J. Food insecurity is associated with overweight in children younger than 5 years of age. Journal of the American Dietetic Association. 2009; 109:1790-1794. [PubMed: 19782181]

Morin P, Demers K, Turcotte S, Mongeau L. Association between perceived self-efficacy related to meal management and food coping strategies among working parents with preschool children. Appetite. 2013; 65:43-50. [PubMed: 23402715]

Murray DM, Varnell SP, Blitstein JL. Design and analysis of group-randomized trials: A review of recent methodological developments. American Journal of Public Health. 2004; 94:423-432. [PubMed: 14998806]

Nader P, O’Brien M, Houts R, Bradley R, Belsky J, Crosnoe R, Friedman S, Mei Z, Susman E. the National Institute of Child Health and Human Development Early Child Care Research Network. Identifying risk for obesity in early childhood. Pediatric. 2006; 118:e594-e601. Available at http:// www.pediatrics.org/cgi/content/full/118/3/e594.

National Center for Health Statistics. National Health and Nutrition Examination Anthropometry Procedures Manual. Hyattsville, MD: U.S. Department of Health and Human Services, Centers for Disease Control and Prevention; 2004. Downloaded from http://www.cdc.gov/nchs/data/nhanes/ nhanes_03_04/BM.pdf. [Accessed on May 23, 2006]

Neumark-Sztainer D, Wall M, Fulkerson J, Larson N. Changes in the frequency of family meals from 1999 to 2010 in the homes of adolescents: Trends by sociodemographic characteristics. Journal of Adolescent Health. 2013; 52:201-206. [PubMed: 23332485] 
Ogden C, Carroll M, Kit B, Flegal K. Prevalence of obesity and trends in body mass index among US children and adolescents, 1999-2019. JAMA. 2012; 307:483-490. [PubMed: 22253364]

Patrick H, Nicklas T. A review of family and social determinants of children's eating patterns and diet quality. Journal of the American College of Nutrition. 2013; 24:83-92. [PubMed: 15798074]

Patrick H, Nicklas T, Hughes S, Morales M. The benefits of authoritative feeding style: Caregiver feeding styles and children's food consumption patterns. Appetite. 2005; 44:243-249. [PubMed: 15808898]

Powers S, Chamberlin L, van Schaick K, Sherman S, Whitaker R. Maternal feeding strategies, child eating behaviors, and child BMI in low-income African-American preschoolers. Obesity. 2006; 14:2026-2033. [PubMed: 17135620]

Office of Minority Health. Minority health facts: Hispanics/Latinos in Rhode Island. Providence, RI: Rhode Island Department of Health; 2011.

Radloff L. The CES-D scale: A self-report depression scale for research in the general population. Applied Psychological Measurement. 1977; 1:385-401.

Reidpath D, Burns C, Garrard J, Mahoney M, Townsend M. An ecological study of the relationship between social and environmental determinants of obesity. Health and Place. 2008; 8:141-146. [PubMed: 11943585]

Rollins B, Belue R, Francis L. The beneficial effect of family meals on obesity differs by race sex, and household education: The National Survey of Child Health 2003-2004. Journal of the American Dietetic Association. 2010; 110:1335-1339. [PubMed: 20800125]

Sanders M, Woolley M. The relationship between maternal self-efficacy and parenting practices: implications for parent training. Child: Care, Health and Development. 2005; 31:65-73.

Scaglioni S, Arrizza C, Vecchi F, Tedeschi S. Determinants of children's eating behavior. American Journal of Clinical Nutrition. 2011; 94(supplement):2006S-2011S. [PubMed: 22089441]

Silver E, Heneghan A, Bauman L, Stein R. The relationship of depressive symptoms to parenting competence and social support in inner-city mothers of young children. Maternal and Child Health Journal. 2006; 10:105-112. [PubMed: 16382333]

Sobolewski J, Amato P. Economic hardship in the family of origin and children's psychological wellbeing in adulthood. Journal of Marriage and the Family. 2005; 67:141-156.

Valdes J, Rodriguez-Artalejo F, Casquero MB, Royo-Bordonada MA. Frequency of family meals and childhood overweight: a systematic review. Pediatric Obesity. 2012; 8:E1-E13. [PubMed: 23239547]

Ventura A, Birch L. Does parenting affect children's eating and weight status? International Journal of Behavioral Nutrition and Physical Activity. 2008; 5:15. from http://www.ijbnpa.org/content/ 5/1/15. [PubMed: 18346282]

Weissman M, Sholomskas D, Pottenger M, Prusoff B, Locke B. Assessing depressive symptoms in five psychiatric populations: A validation study. American Journal of Epidemiolology. 1977; 106:203-214.

Wojcicki JM, Holbrook K, Lustig RH, Epel E, Caughey A, Munoz M, Shiboski S, Heyman M. Chronic maternal depression is associated with reduced weight gain in Latino infants from birth to 2 years of age. PloS ONE. 2011; 6:e16737. http://www.plosone.org/article/info\%3Adoi \%2F10.1371\%2Fjournal.pone.0016737. [PubMed: 21373638]

Woodruff, S.; Harding, R. Family meals and diet quality. In: Preedy, VR.; Hunter, L.; Vinood, B., editors. Diet quality: An evidence-based approach. Vol. Volume 2. New York, NY: Humana Press; 2013. p. 89-100.

Ziegler P, Hanson C, Ponza M, Novak T, Hendricks K. Feeding infants and toddlers study: Meal and snack intakes of Hispanic and non-Hispanic infants and toddlers. Journal of the American Dietetic Association. 2006; 106:S107-S123. [PubMed: 16376635] 


\section{Highlights}

- Maternal depression negatively influenced five types of family food behaviors.

- Caregiver presence while a preschooler eats was linked to lower child BMI z scores.

- Food resource management skills corresponded to child weight status.

- Maternal depression neither directly nor indirectly influenced child weight. 
Table 1

Socio-demographic characteristics of preschool aged children and mothers by child weight status

\begin{tabular}{|c|c|c|c|}
\hline Characteristics & $\begin{array}{l}\text { Healthy Weight } a \\
(n=110) \\
\text { Mean (SD) }\end{array}$ & $\begin{array}{l}\text { Overweight }^{b} \\
(n=54) \\
\text { Mean } \pm \text { SD }\end{array}$ & $\begin{array}{l}\text { Full Sample } \\
(n=164) \\
\text { Mean } \pm \text { SD }\end{array}$ \\
\hline Maternal age (years) & $29.6(7.2)$ & $30.9(7.2)$ & $30.1(7.2)$ \\
\hline Household size & $4.1(1.5)$ & $4.0(1.2)$ & $4.1(1.4)$ \\
\hline Maternal Body Mass Index & $28.3(7.9)$ & $31.0(6.6)^{*}$ & $29.2(7.6)$ \\
\hline Maternal education (years) & $12.9(3.3)$ & $12.0(3.0)$ & $12.6(3.3)$ \\
\hline \multirow[t]{2}{*}{ Child age (months) } & $51.0(9.8)$ & $52.2(10.7)$ & $51.4(10.1)$ \\
\hline & $\%$ & $\%$ & $\%$ \\
\hline Married/lives with partner & 39.1 & 48.1 & 42.1 \\
\hline Hispanic ethnicity & 50.0 & 64.8 & 54.9 \\
\hline Speaks only Spanish in home & 22.7 & 29.6 & 25.0 \\
\hline $\operatorname{SNAP}^{c}$ participation & 62.7 & 63.0 & 62.8 \\
\hline $\mathrm{WIC}^{d}$ participation & 60.0 & 64.8 & 61.6 \\
\hline $\mathrm{SNAP}^{c}$ and $\mathrm{WIC}^{d}$ & 80.0 & 83.3 & 81.1 \\
\hline \multicolumn{4}{|l|}{ Household monthly income } \\
\hline$>\$ 1,500$ & 45.0 & $27.8^{*}$ & 39.3 \\
\hline$=\$ 1,500-1,001$ & 22.0 & 33.3 & 25.8 \\
\hline$\leq \$ 1,000$ & 33.0 & 38.9 & 35.0 \\
\hline Mom employed & 77.1 & 70.4 & 74.8 \\
\hline Household Food Insecure & 40.9 & 48.1 & 42.7 \\
\hline Child Food Insecure & 22.9 & 27.8 & 24.4 \\
\hline Child male & 59.1 & 48.1 & 55.5 \\
\hline Child breastfed yes & 61.1 & 61.1 & 61.1 \\
\hline
\end{tabular}

${ }^{a}$ BMI z score between 5 th and $85^{\text {th }}$ percentile.

${ }^{b} \mathrm{BMI} z$ score $\geq 85^{\text {th }}$ percentile.

${ }^{c}$ SNAP=Supplemental Nutrition Assistance Program.

$d_{\text {WIC }}=$ Special Supplemental Nutrition Program for Women, Infants and Children.

${ }^{*}<.05$ between healthy and overweight groups. 
Table 2

Means, Standard Deviations, Variances, and Ranges of the Independent Variables

\begin{tabular}{|l|r|l|l|}
\hline Independent Variables & $\boldsymbol{M}(\boldsymbol{S D})$ & Variance & $\begin{array}{l}\text { Actual Range } \\
\text { (Possible Range) }\end{array}$ \\
\hline Maternal CES-D ${ }^{a}$ scores & $11.1(0.7)$ & 82.8 & $0-43(0-60)$ \\
Family Mealtime Practices & & & \\
Maternal presence when child eats & $16.1(3.3)$ & 11.2 & $4-20(0-20)$ \\
Maternal control of mealtime routines & $13.3(4.6)$ & 20.9 & $1-20(0-20)$ \\
Child control of snacking & $3.5(3.0)$ & 9.1 & $0-12(0-12)$ \\
Negative mealtime practices & $5.4(3.7)$ & 13.7 & $0-15(0-16)$ \\
Food resource management skills & $16.0(2.9)$ & 8.3 & $4-20(4-20)$ \\
\hline
\end{tabular}

${ }^{a}$ CES-D $=$ Center for Epidemiologic Studies-Depression Scale 


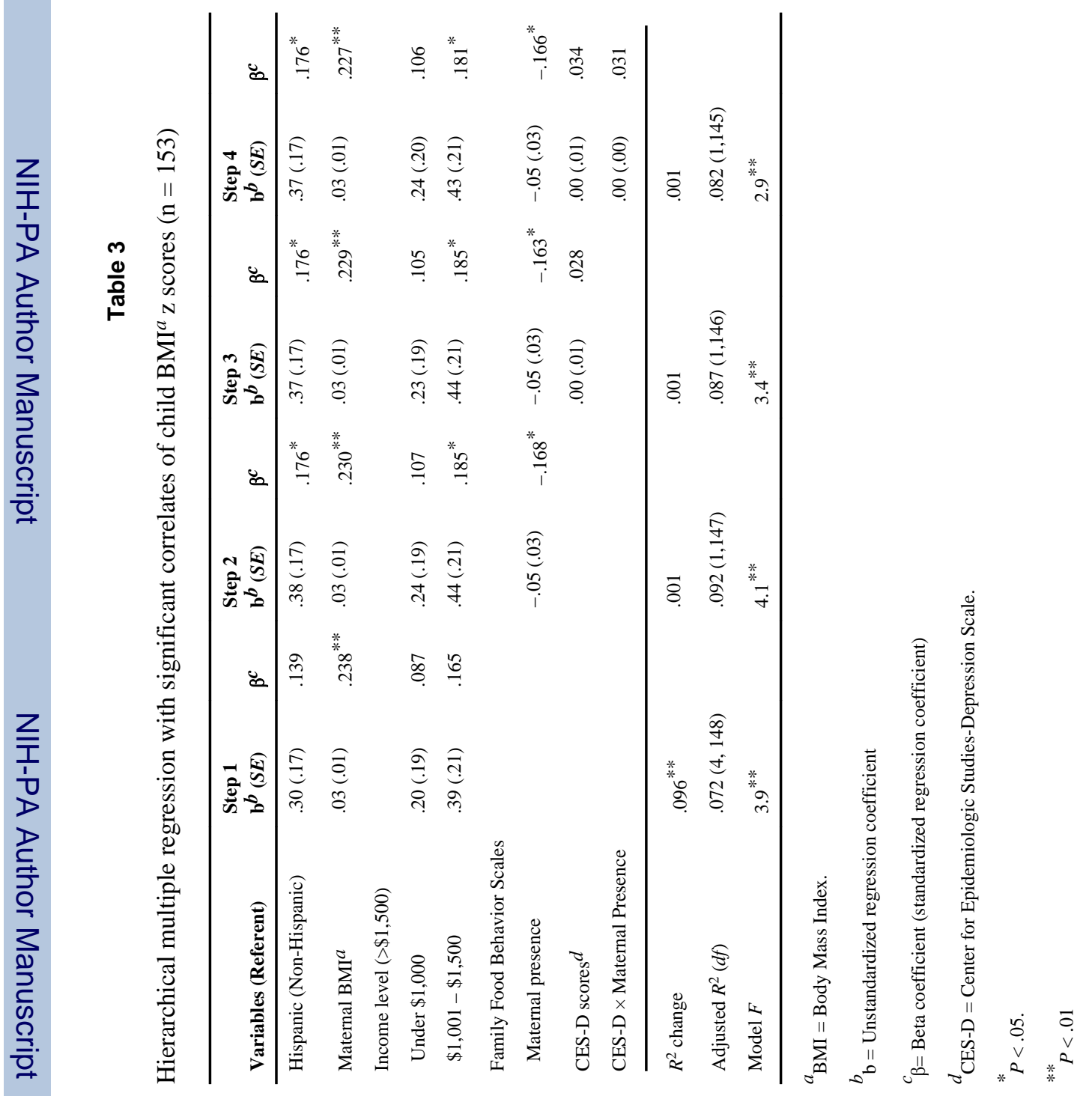


Table 4

Hierarchical logistic regression with significant correlates of child overweight $(\mathrm{n}=153)$

\begin{tabular}{|c|c|c|c|c|}
\hline Variables (Referent) & $\begin{array}{l}\text { Step 1 } \\
\operatorname{AOR}^{a}\left(95 \% \mathrm{CI}^{b}\right)\end{array}$ & $\begin{array}{l}\text { Step } 2 \\
\operatorname{AOR}^{a}\left(95 \% \mathrm{CI}^{b}\right)\end{array}$ & $\begin{array}{l}\text { Step } 3 \\
\operatorname{AOR}^{a}\left(95 \% \mathrm{CI}^{b}\right)\end{array}$ & Step 4 \\
\hline Hispanic (Non-Hispanic) & $1.77(0.85-3.68)$ & $1.93(0.90-4.14)$ & $1.93(0.90-4.12)$ & $1.95(0.91-4.21)$ \\
\hline Maternal BMI ${ }^{c}$ & $1.06(1.01-1.10)^{*}$ & $1.01(1.01-1.10)^{*}$ & $1.05(1.01-1.10)^{*}$ & $1.06(1.01-1.11)^{*}$ \\
\hline \multicolumn{5}{|l|}{ Income level $(>\$ 1,500)$} \\
\hline Under $\$ 1,000$ & $1.66(0.72-3.86)$ & $2.10(0.86-5.13)$ & $2.18(0.88-5.39)$ & $2.18(0.88-5.38)$ \\
\hline$\$ 1,001-\$ 1,500$ & $2.36(0.98-5.68)$ & $3.68(1.40-9.69)^{* *}$ & $3.85(1.44-10.29)^{* *}$ & $3.93(1.47-10.49)^{* *}$ \\
\hline \multicolumn{5}{|l|}{ Family food behavior scales } \\
\hline Food resource management skills & & $0.83(0.72-0.95)^{* *}$ & $0.82(0.71-0.94)^{* *}$ & $0.82(0.71-0.95)^{* *}$ \\
\hline CES-D ${ }^{d}$ scores & & & $0.99(0.95-1.03)$ & $0.98(0.94-1.02)$ \\
\hline CES-D ${ }^{d} \times$ Food resource management skills & & & & $0.99(0.98-1.01)$ \\
\hline Step $\chi^{2}$ & $11.53^{*}$ & $8.16^{* *}$ & 0.41 & 1.02 \\
\hline Model $\chi^{2}$ & $11.53^{*}$ & $19.69^{* *}$ & $20.10^{* *}$ & $21.12^{* *}$ \\
\hline-2 Log Likelihood & 183.23 & 175.09 & 174.68 & 173.657 \\
\hline
\end{tabular}

${ }^{a} \mathrm{AOR}=$ Adjusted odds ratio.

${ }^{b} \mathrm{CI}=$ Confidence interval.

$c_{\mathrm{BMI}}=$ Body Mass Index.

$d_{\text {CES-D }}=$ Center for Epidemiologic Studies - Depression Scale.

${ }^{*}<$ <.05.

*** $P<.01$. 